\title{
Southeastern U.S.A. continental shelf respiratory rates revisited
}

\author{
Joan E. Sheldon - Peter C. Griffith - Francesc Peters • \\ Wade M. Sheldon Jr. • Jackson O. Blanton • Julie Amft • \\ Lawrence R. Pomeroy
}

Received: 26 July 2010/Accepted: 11 November 2010/Published online: 25 November 2010

(C) Springer Science+Business Media B.V. 2010

\begin{abstract}
Respiratory rates on the U. S. southeastern continental shelf have been estimated several times by different investigators, most recently by Jiang et al. (Biogeochemistry 98:101-113, 2010) who report lower mean rates than were found in earlier work and attribute the differences to analytical error in all methods used in earlier studies. The differences are, instead, attributable to the differences in the geographical scope of the studies. The lower estimates of regional organic carbon flux of Jiang et al. (Biogeochemistry 98:101-113, 2010) are a consequence of their extrapolation of data from a small portion of the shelf to the entire South Atlantic
\end{abstract}

J. E. Sheldon $(\varangle) \cdot$ W. M. Sheldon Jr.

Department of Marine Sciences, University of Georgia, Athens, GA 30602-3636, USA

e-mail: jsheldon@uga.edu

P. C. Griffith

Sigma Space Corporation, Carbon Cycle and Ecosystems Office, Code 614.4, NASA Goddard Space Flight Center, Greenbelt, MD 20711, USA

F. Peters

Institut de Ciencies del Mar, CSIC, Pg Maritim de la Barcelona 37-49, 08003 Barcelona, Spain

J. O. Blanton · J. Amft

Skidaway Institute of Oceanography, 10 Ocean Science

Circle, Savannah, GA 31411, USA

L. R. Pomeroy

Institute of Ecology, University of Georgia, Athens,

GA 30602-2202, USA
Bight. This comment examines the methodologies used as well as the variability of respiratory rates in this region over space and time.

Keywords Microbial respiration - Southeastern U. S. continental shelf · Dissolved oxygen · Bacteria

\section{Introduction}

The question of whether continental margins are net heterotrophic or autotrophic is important from the standpoint of global biogeochemical budgets (Liu et al. 2010). The continental shelf of the southeastern U. S. has been the subject of repeated studies (Anderson et al. 1956-1959; Atkinson et al. 1985; Pomeroy et al. 2000) but many questions about it remain unresolved. A recent study (Jiang et al. 2010) attempts to resolve a perceived carbon imbalance in the South Atlantic Bight (SAB) by estimating mean organic carbon flux over the region using newly presented pelagic community respiratory rates. This commentary suggests the requirements of an adequate model for estimating mean respiratory rate in the SAB and examines the results of Jiang et al. (2010) and previous studies in light of this goal.

\section{Spatial and temporal variability of shelf processes}

The southeastern U.S. continental shelf is a varied and dynamic region (Lee et al. 1991; Kourafalou 
et al. 1996a, b). The SAB is approximately $1,200 \mathrm{~km}$ in length, $120 \mathrm{~km}$ in width at its widest point off Georgia, 50-75 m deep at the shelf break, and spans $8.5^{\circ}$ latitude. A number of rivers, from small coastal plain drainages with little net flow to large navigable rivers, contribute freshwater and terrestrially derived nutrients and organic matter. Subannual variations in atmospheric temperature, wind, and river flow create seasonally variable cross-shelf gradients in water temperature and salinity as well as seasonal stratification (Menzel 1993). The alternation between river plumes and tidally flushed lagoons creates alongshore variability in salinity and terrestrially derived substances near shore. Sporadic intrusions of upwelled water from the shelf break also affect the temporal and spatial variability of physical conditions, nutrient availability, and primary production on the shelf (Menzel 1993). A semi-permanent gyre, formed as the Gulf Stream passes over the Charleston Bump at latitude $32^{\circ} \mathrm{N}$, promotes upwelling that supports locally elevated rates of primary production. The circulation of the gyre creates an area to the north, off Cape Fear, where mean shoreward transport of fixed nitrogen across the shelf break is enhanced and another area to the south, between Savannah and Charleston, where offshore nitrate transport is maximized (Jahnke and Blanton 2010). As a result of this physical regime, previous studies have found variability in biological processes on different parts of the southeastern shelf (Bishop et al. 1980; Paffenhöfer 1985; Pomeroy et al. 2000).

A model that seeks to estimate a material flux in a region over an annual or longer timescale must carefully consider both temporal and spatial averaging of data to ensure that seasonality, interannual variability, and spatial variability are adequately represented. Microbial respiration, a large component of the pelagic community respiration in the SAB (Griffith et al. 1990), is fundamentally a small-scale phenomenon dependent on local conditions including temperature and substrate availability (Wiebe et al. 1993). In the case of the SAB, adequate sampling over time and space should include seasonal estimates of respiratory rate for locations that represent, at a minimum, the cross-shelf gradients in temperature, salinity, and depth and the along-shelf gradients in organic matter input from rivers and marshes. Variability due to intrusions of upwelled water can only be accounted for by repeated sampling throughout the region, and this makes it difficult to estimate a regional long-term mean respiratory rate with any certainty.

A previous study (Pomeroy et al. 2000) gathered respiratory rate measurements (including those from Griffith and Pomeroy 1995) that were collected across the shelf over a decade (1990-1999) and spanned nearly $6^{\circ}$ of latitude, from Cape Canaveral, FL to Cape Fear, NC (Fig. 1). In contrast, Jiang et al. (2010, see their Fig. 1 and Fig. 1 here) measured microbial respiration over a 3-year period (June 2003-May 2006) along three transects across the continental shelf off Georgia that spanned $70 \mathrm{~km}$ (approximately $0.5^{\circ}$ latitude) on the landward side (Wassaw Sound to Doboy Sound) and converged at a single station near the shelf break. Thus, the area covered by Jiang et al. (2010) represents only about $10 \%$ of the SAB and ends just north of the outflow of the Altamaha River, which delivers an average of

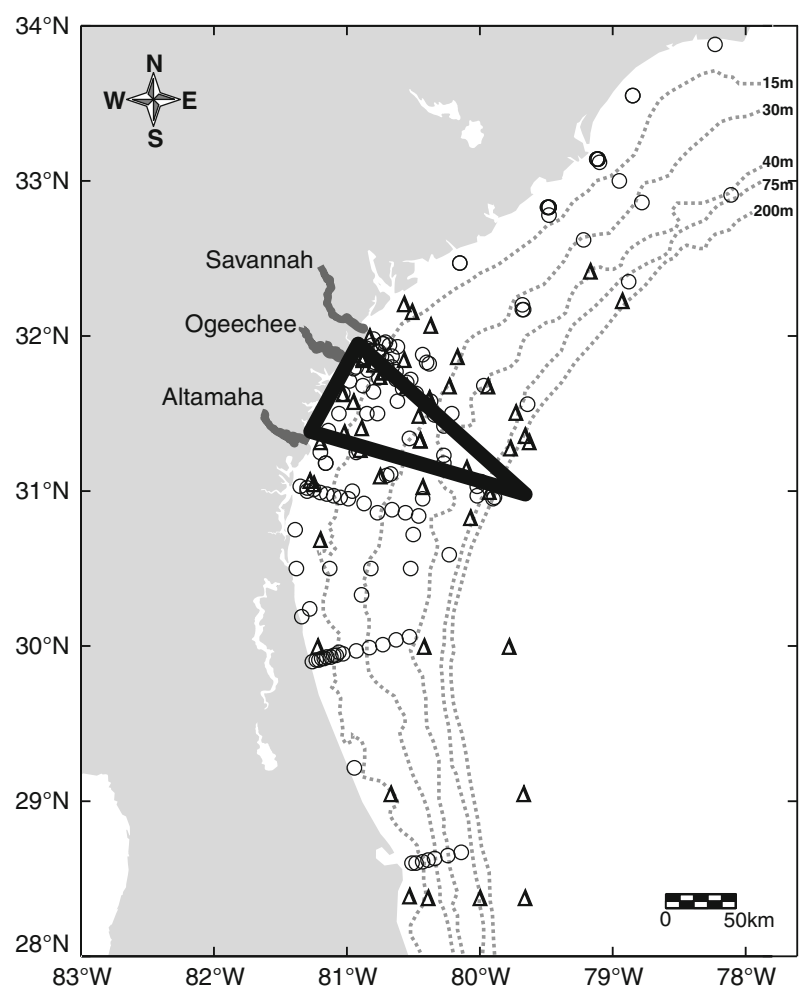

Fig. 1 The South Atlantic Bight, from Cape Fear, NC to Cape Canaveral, FL. Symbols show the locations of respiratory rate measurements reported in Pomeroy et al. 2000 (small triangles), including those of Griffith and Pomeroy (1995) (circles). The heavy triangular outline shows the area sampled by Jiang et al. (2010). The larger rivers emptying into this section of the Bight and depth contours on the continental shelf are labeled for geographical reference 
Table 1 Comparison of seasonal mean community respiratory rates (mmole $\mathrm{m}^{-3} \mathrm{~d}^{-1}$ ) measured by Jiang et al. (2010) and Pomeroy et al. (2000) in the continental shelf off northern Georgia, USA

\begin{tabular}{llll}
\hline & Jiang et al. 2010 & Pomeroy et al. 2000 & $\begin{array}{l}\text { Locations } \\
\text { (Pomeroy et al. 2000) }\end{array}$ \\
\hline $\begin{array}{lll}\text { Inner shelf } \\
\text { Winter }\end{array}$ & 2.9 & 1.8 & St. Catherines Sea Buoy \\
& & 5.4 & $\begin{array}{l}\text { Ogeechee/Ossabaw estuary } \\
\text { Wassaw Sea Buoy }\end{array}$ \\
Summer & 15.5 & 10.1 & Ogeechee/Ossabaw estuary \\
Mid-shelf & & 17.7 & \\
Winter & 1.3 & 2.5 & Gulf Stream \\
Outer shelf & & 7.5 & Shelf break \\
Winter & 0.8 & $<0.1$ & \\
Summer & 1.8 & & \\
\end{tabular}

$400 \mathrm{~m}^{3} \mathrm{~s}^{-1}$ freshwater to the shelf. Since the mean flow on the inner shelf is generally southward (Menzel 1993), it is likely that the samples of Jiang et al. (2010) do not include the area influenced by the largest river outflow on the Georgia coast.

Jiang et al. (2010, see their Table 2) report mean respiratory rates that are lower than those reported in all earlier studies. In light of the differences in physical and temporal scope between this and the earlier studies, it is not surprising that different mean respiratory rates were found. The study by Jiang et al. (2010) can be viewed as a later investigation of a subset of the region studied by Pomeroy et al. (2000, including earlier works referenced therein). In this context, the rates reported by Jiang et al. (2010) may be compared with the earlier results (Pomeroy et al. 2000, see their Tables 1 and 4) from this sub-region (Table 1). On the inner shelf, the winter and summer mean respiratory rates reported by Jiang et al. (2010) are between the rates measured at two locations in each season by Pomeroy et al. (2000). On the midshelf, winter rates are comparable. Outer shelf rates differed between the two studies, although the stations used here from Pomeroy et al. (2000) are on the far eastern edge of the shelf. In winter, the higher rate was measured by Pomeroy et al. (2000), and in summer, the higher rate was measured by Jiang et al. (2010). Thus mean respiratory rates measured by the two groups in the same general area were comparable, in spite of the fact that they were measured years apart. The differences in overall mean respiratory rates reported in the two studies are therefore likely due, at least in part, to the larger area covered by Pomeroy et al. (2000) (including Griffith and Pomeroy 1995).

Estimates of total primary production for the southeastern shelf are approximately 46-50 $\mathrm{Tg} \mathrm{C} \mathrm{y}^{-1}$ from in situ estimates (Menzel 1993; Jahnke et al. 2000) or from satellite data (Longhurst et al. 1995). These estimates are net in the sense that they include respiration, so gross primary production should be substantially larger. Thus, the respiratory rate of $45 \mathrm{Tg}$ $\mathrm{Cy}^{-1}$ computed by Jiang et al. (2010) would suggest an autotrophic shelf, rather than the balance that they propose. This contrasts with the generalization of Smith and Mackenzie (1987) that continental shelves, except those on western continental margins having coastal upwellings, are heterotrophic. As Pomeroy et al. (2000) documented, the southeastern shelf lacks the high secondary productivity that would be expected of a net autotrophic shelf.

The calculations of Jiang et al. (2010) are based on the assumption that respiratory rates in their closelyspaced transects of surface samples can be extrapolated in three dimensions. The analysis above suggests that their samples are not representative of much of the area included in their model. Furthermore, they extrapolate their surface measurements to depth, in spite of demonstrated seasonal stratification in the area that they did sample. This same research group has examined $\mathrm{pCO}_{2}$ in the $\mathrm{SAB}$ and found that the shelf off Wassaw Sound is not representative of the SAB as a whole in that regard. Earlier studies (Cai et al. 2003; Wang et al. 2005) based on a single transect off Wassaw Sound led to the conclusion that the $\mathrm{SAB}$ is a net source of $\mathrm{CO}_{2}$ to the atmosphere, but 
a later study (Jiang et al. 2008) that included transects from Cape Lookout, NC to Cape Canaveral, FL concluded that overall, the SAB is a net sink for atmospheric $\mathrm{CO}_{2}$ on an annual basis. Chen and Borges (2009) point out several examples, including this one, where limited vs. more complete studies of a shelf region led to opposite conclusions about the region's status as a source or sink of $\mathrm{CO}_{2}$.

A study of planktonic community respiration in the East China Sea that covered over $6^{\circ}$ of latitude south of the Changjiang River outflow and from the nearshore zone to the shelf break found that summer community respiration varied over 1-2 orders of magnitude spatially, with areas of highest respiration varying temporally as well (Chen et al. 2009). The mean outflow of the Changjiang River is about 75 times that of each of the largest rivers entering the $\mathrm{SAB}$, so the relative influences of riverine inputs and Kuroshio upwelling intrusions may be different from the situation in the $\mathrm{SAB}$, but this study highlights the spatial and temporal variability in community respiration that may be found in subtropical continental shelves.

\section{Measurement of respiratory rates}

There were also differences in the methods used to measure microbial respiration in the two SAB studies, and Jiang et al. (2010) speculated that these differences were the primary cause of the disparities in overall mean respiratory rates. Their assertions about earlier methodologies are examined below.

Jiang et al. (2010) referred to a criticism of oxygen consumption by ICI electrodes (McKinnon et al. 2007) to suggest that the electrode-based measurements of respiratory rate by Griffith et al. (1990) and Griffith and Pomeroy (1995) were too high. Griffith used Nester electrodes, which had an oxygen consumption rate of $<10^{-4} \mu \mathrm{mol} \mathrm{O}_{2} \mathrm{~h}^{-1}$. As shown in Fig. 4 of Griffith (1988), this had a negligible effect on respiratory rates measured for 1-2 $\mathrm{h}$. The use of Nester electrodes was discontinued because they were no longer available commercially, not because they did not perform well. More recently, GarcíaMartín et al. (2010) have reported success with Unisense oxygen microelectrodes with similarly low oxygen consumption rates.
Jiang et al. (2010) also criticized the use of dry incubators for temperature control in later studies that measured oxygen consumption in bottles using precision Winkler titration (Pomeroy et al. 2000), asserting that neck-drying of BOD bottles can lead to errors in oxygen measurement. The study cited for this (Labasque et al. 2004) was actually questioning dry storage of fixed samples for $>1$ day, not recommending short-term incubation conditions. Nevertheless, introduction of air bubbles during dry incubation must be avoided. The earlier measurements of Pomeroy et al. (2000) used dissolved oxygen (DO) bottles with the fluted tops filled with water, which is the conventional procedure for preventing bubble formation. Later measurements in this same study used $125 \mathrm{ml}$ borosilicate glass, screw-cap bottles having a conical plastic cap liner that expressed water from the bottle as it was closed. Bubbles never occurred in either type of bottle.

Temperature control during incubations is important in order to maintain the conditions at the time of sampling. The dry incubators used by Pomeroy et al. (2000) allowed for precise temperature control. Temperature in the incubators was monitored with a remote-reading thermometer, and extra control bottles were checked with a thermometer to further verify a constant and correct temperature in the bottles. Use of more than one incubator was important when incubating onshore and offshore samples from very different in situ temperatures concurrently. Studies that use flowing seawater bath incubators on deck (Jiang et al. 2010) run the risk of changing temperatures during the incubation, especially in winter when sea temperatures (and presumably bath temperatures) can vary as much as $10^{\circ} \mathrm{C}$ along a cross-shelf transect. No evidence was given by Jiang et al. (2010) regarding temperature control during deck incubations. If the ship was underway crossing the shelf during incubations, then presumably bath temperatures were not held constant.

It is desirable to measure respiratory rates over the shortest possible time in order to avoid changing sample conditions during the measurement, either through oxygen consumption by electrodes or by community changes associated with confinement of the sample in a bottle. The electrode-based measurements of Griffith et al. (1990) and Griffith and Pomeroy (1995) employed a computer program that calculated respiratory rates continuously in real time 
from thousands of DO measurements (Griffith 1988). Each small water sample was incubated for the briefest duration needed to obtain statistically significant rates, typically 45-90 $\mathrm{min}$ and at most $2 \mathrm{~h}$. Samples were maintained at the same temperature observed at the depth from which they were collected. The 12-h incubations and precision Winkler titrations used by Pomeroy et al. (2000) followed methods described earlier (Pomeroy et al. 1994) that documented no growth of microbial films in bottles and linear oxygen uptake for at least $12 \mathrm{~h}$. Further precision was assured by using five replicates for both initial and final measurements (Pomeroy et al. 2000). In contrast, Jiang et al. (2010) used fewer bottles (three per time point) and incubated them for $24 \mathrm{~h}$. Their claim that 12-h incubations may have suffered from nonlinear DO decreases while their 24-h incubations did not is counter to the conventional wisdom that bottle effects increase over time, an idea supported by a detailed study of the time course of changes in respiration during bottle incubations (Pomeroy et al. 1994). A recent study that compared the Winkler and microelectrode methods using timecourse dark incubations reiterated that the results from the two methods are statistically comparable and that community respiratory rates were generally stable over periods ranging from 6 to $24 \mathrm{~h}$ for samples taken in the Ría de Vigo (Spain) during late summer through winter (García-Martín et al. 2010).

Jiang et al. (2010) also maintain that the use of larger bottles $(300 \mathrm{ml})$ was an improvement over the smaller bottles $(125 \mathrm{ml})$ used in earlier studies (Pomeroy et al. 2000). Two recent studies have examined the alleged volumetric bottle effect on microbial growth (Hammes et al. 2010) and plankton community respiration (García-Martín et al. 2010) and found none.

Jiang et al. (2010) raise the issue of possible peroxide production and thus the need for killed controls. Having on one occasion found net oxygen production in the dark in samples from Wassaw Sound, Georgia (LRP unpublished data), using killed controls in addition to time-zero measurements would have been a more conservative approach. However, this does not seem to be a general problem affecting respiratory rate measurements in the $\mathrm{SAB}$, because Jiang et al. (2010) themselves found no differences in DO concentrations between time-zero measurements and incubated killed controls.

\section{Conclusions}

It was neither necessary nor appropriate to suggest that methods used in earlier studies were faulty and led to differences in measured respiratory rates (Jiang et al. 2010). In fact, the temperature control during winter measurements by Jiang et al. (2010) is questionable owing to the use of flowing seawater incubators. It is likely that the lower estimate of SAB mean respiratory rate by Jiang et al. (2010) is instead a consequence of extrapolation of surface measurements taken on a small portion of the shelf. While their measurements of respiratory rate were comparable to those found previously in the same small area, the earlier study of broader scope (Pomeroy et al. 2000) reported higher overall rates for the region. This indicates that the area studied by Jiang et al. (2010) is not representative of the whole, and the extrapolation of their data to represent the entire $\mathrm{SAB}$ resulted in a severe underestimation of the mean organic carbon flux over the region.

Acknowledgments J. E. Sheldon and W. M. Sheldon, Jr. were supported by the Georgia Coastal Ecosystems Long-Term Ecological Research program (National Science Foundation award number 0620959).

\section{References}

Anderson WW, Gehringer JW, Cohen E (1956-1959) Physical oceanographic, biological, and chemical data-South Atlantic coast of the United States. U. S. Fish Wildl Ser Spec Sci Rep Fish, 178, 198, 210, 234, 248, 265, 278

Atkinson LP, Menzel DW, Bush KA (eds) (1985) Oceanography of the southeastern U.S. continental shelf, vol 2. American Geophysical Union, Washington DC

Bishop SS, Yoder JA, Paffenhöfer G-A (1980) Phytoplankton and nutrient variability along a cross-shelf transect off Savannah, Georgia, USA. Estuar Coast Shelf Sci 11: 359-368

Cai W-J, Wang ZA, Wang Y (2003) The role of marsh-dominated heterotrophic continental margins in transport of $\mathrm{CO}_{2}$ between the atmosphere, the land-sea interface and the ocean. Geophys Res Lett 30(16):1849-1852

Chen C-TA, Borges AV (2009) Reconciling opposing views on carbon cycling in the coastal ocean: continental shelves as sinks and near-shore ecosystems as sources of atmospheric $\mathrm{CO}_{2}$. Deep Sea Res II 56:578-590

Chen C-C, Shiah F-K, Chiang K-P, Gong G-C, Kemp WM (2009) Effects of the Changjiang (Yangtze) river discharge on planktonic community respiration in the East China Sea. J Geophys Res 114:C03005. doi:10.1029/ 2008JC004891 
García-Martín EE, Serret P, Pérez-Lorenzo M (2010) Testing potential bias in marine plankton respiration rates by dark bottle incubations in the NW Iberian shelf: incubation time and bottle volume. Cont Shelf Res (in press)

Griffith PC (1988) A high-precision respirometer for measuring small rates of change in the oxygen concentration of natural waters. Limnol Oceanogr 33(4):632-638

Griffith PC, Pomeroy LR (1995) Seasonal and spatial variations in pelagic community respiration on the southeastern US continental shelf. Cont Shelf Res 15(7):815-825

Griffith PC, Douglas DJ, Wainright SC (1990) Metabolic activity of size-fractionated microbial plankton in estuarine, nearshore, and continental shelf waters of Georgia. Mar Ecol Prog Ser 59:263-270

Hammes F, Vital M, Egli T (2010) Critical evaluation of the volumetric "bottle effect" on microbial batch growth. Appl Environ Microbiol 76(4):1278-1281

Jahnke RA, Blanton JO (2010) The Gulf Stream. In: Liu K-K, Atkinson LP, Quiñones RA, Talaue-McManus L (eds) Carbon and nutrient fluxes in continental margins: a global synthesis. Global change-the IGBP series. Springer, Stockholm, pp 146-153. doi:10.1007/978-3-540-92735-8

Jahnke RA, Nelson JR, Marinelli FL, Eckman JE (2000) Benthic flux of biogenic elements on the southeastern U.S. continental shelf: influence of pore water advective transport and benthic algae. Cont Shelf Res 20:109-127

Jiang L-Q, Cai W-J, Wanninkhof R, Wang Y, Lüger H (2008) Air-sea $\mathrm{CO}_{2}$ fluxes on the U.S. South Atlantic Bight: spatial and seasonal variability. J Geophys Res 113:C07019. doi:10.1029/2007JC004366

Jiang L-Q, Cai W-J, Wang Y, Diaz J, Yager PL, Hu X (2010) Pelagic community respiration on the continental shelf off Georgia, USA. Biogeochemistry 98:101-113

Kourafalou VH, Oey L-Y, Wang JD, Lee TN (1996a) The fate of river discharge on the continental shelf 1 . Modeling the river plume and inner shelf coastal current. J Geophys Res Ocean 101:3425-3434

Kourafalou VH, Lee TN, Oey L-Y, Wang JD (1996b) The fate of river discharge on the continental shelf 2 . Transport of low-salinity coastal waters under realistic wind and tidal forcing. J Geophys Res Ocean 101:3435-3455

Labasque T, Chaumery C, Aminot A, Kergoat G (2004) Spectrophotometric Winkler determination of dissolved oxygen: re-examination of critical factors and reliability. Mar Chem 88:53-60
Lee TN, Yoder JA, Atkinson LP (1991) Gulf Stream frontal eddy influence on productivity of the southeast U.S. continental shelf. J Geophys Res Ocean 96(12): 22191-22205

Liu K-K, Atkinson LP, Quiñones RA, Talaue-McManus L (2010) Biogeochemistry of continental margins in a global context. In: Liu K-K, Atkinson LP, Quiñones RA, TalaueMcManus L (eds) Carbon and nutrient fluxes in continental margins: a global synthesis. Global change-the IGBP series. Springer, Stockholm, pp 3-24. doi:10.1007/ 978-3-540-92735-8

Longhurst A, Sathyendranath S, Platt T, Cayerhill C (1995) An estimate of global primary production in the ocean from satellite radiometer data. J Plankton Res 17:1245-1271

McKinnon AD, Carleton JH, Duggan S (2007) Pelagic production and respiration in the Gulf of Papua during May 2004. Cont Shelf Res 27:1643-1655

Menzel DW (ed) (1993) Ocean processes: U.S. southeast continental shelf. U.S. Department of Energy, Office of Scientific and Technical Information, Oak Ridge

Paffenhöfer G-A (1985) The abundance and distribution of zooplankton on the southeastern shelf of the United States. In: Atkinson LP, Menzel DW, Bush KA (eds) Oceanography of the southeastern U.S. continental shelf. American Geophysical Union, Washington DC, pp 104-117

Pomeroy LR, Sheldon JE, Sheldon WM Jr (1994) Changes in bacterial numbers and leucine assimilation during estimations of microbial respiratory rates in seawater by the precision Winkler method. Appl Environ Microbiol 60(1):328-332

Pomeroy LR, Sheldon JE, Sheldon WM Jr, Blanton JO, Amft J, Peters F (2000) Seasonal changes in microbial processes in estuarine and continental shelf waters of the southeastern U.S.A. Estuar Coast Shelf Sci 51:415-428

Smith SV, Mackenzie FT (1987) The ocean as a net heterotrophic system: implications from the carbon biogeochemical cycle. Glob Biogeochem Cycles 1(3):187-198

Wang ZA, Cai W-J, Wang Y, Ji H (2005) The southeastern continental shelf of the United States as an atmospheric $\mathrm{CO}_{2}$ source and an exporter of inorganic carbon to the ocean. Cont Shelf Res 25:1917-1941

Wiebe WJ, Sheldon WM Jr, Pomeroy LR (1993) Evidence for an enhanced substrate requirement by marine mesophilic bacterial isolates at minimal growth temperatures. Microb Ecol 25:151-159 